\title{
STUDY ON THE ECOLOGICAL COMPENSATION SHARING IN THE CENTRAL LINE OF THE SOUTH-TO-NORTH WATER DIVERSION PROJECT
}

\author{
LIU, S. J. ${ }^{1}-$ ZHANG, W. H. ${ }^{1 *}-$ YUN, J. W. ${ }^{1}-$ KOU, Q. Q. ${ }^{1}-$ BAO, L. L. ${ }^{2}-$ LIU, J. J. ${ }^{2}$ \\ ${ }^{1}$ Laboratory of Water Resource and Hydrology, College of Resources and Environment \\ Southwest University, Chongqing 400715, China \\ ${ }^{2}$ Chongqing Water Conservancy and Electricity Architectural Survey and Design Institute \\ Chongqing 400700, China \\ Corresponding author \\ e-mail: swuwater@126.com; phone: +86-136-3782-2374
}

(Received $2^{\text {nd }}$ Apr 2019; accepted $13^{\text {th }}$ Jun 2019)

\begin{abstract}
The way to calculate and share the total amount of ecological compensation for inter-basin water transfer project is directly related to the enthusiasm of the water-receiving area in participating in the ecological protection of the water source area. This paper takes the water source area of the South-toNorth Water Diversion Project and the water-receiving areas of Beijing, Tianjin, Hebei and Henan as the research objects, and using the single-index method, the comprehensive index method and the deviation method to make appropriate calculation for the ecological compensation amount of 6.248 billion yuan paid to the water source area each year by the water receiving area. The results show that the method of deviation is more objective, comprehensive and reasonable, which can provide a new idea for the ecological compensation apportion calculation of the Central Line of South-to-North Water Diversion Project.
\end{abstract}

Keywords: inter-basin water transfer, water conservation, Shaanxi water source area, resource allocation, water trading, deviation method

\section{Introduction}

Water is the source of all life and an important factor affecting human survival and development. The uneven distribution of water resources makes it necessary to build inter-basin water Diversion facilities between multi-water areas and water-deficient areas. Inter-basin water transfer can alleviate the problem of insufficient water savings in water-scarce areas and the imbalance of water resources in time and space effectively (Chen and Huang, 2006). But it changes the water conditions in the areas it passes through, and it will break the original ecological balance in the process of its application and management at the same time. In order to ensure the sufficiency and cleanliness of the water resources obtained by the water receiving area, it is necessary to do a good job in ecological protection of the water source areas and carry out necessary ecological compensation. Ecological compensation which means paying for ecological or environmental services is based on the purpose of ecological protection and the protection of ecosystems and species diversity through the operation of ecological compensation mechanisms (Hansen et al., 2018). Watershed ecological compensation is a powerful economic tool for addressing water management problems (Thieme et al., 2012). Ecological compensation involves measures to create positive conservation outcomes intended to offset the residual impacts of development (Brown et al., 2014). The inter-basin ecological compensation scheme is the result of the interaction between 
upstream and downstream cities, and is of great significance for the guidance of regional economic development (Zhang et al., 2018).

The ecological compensation of the river basin originated from the management and planning of the ecological service market. In the 1960s, soil erosion seriously affected the quality of living environment of the basin residents. To compensate the watershed residents, the US Tennessee Valley Authority (TVA) (Zhang and Liu, 2006) increased the protection of natural resources in the basin, and the prototype of the ecological compensation mechanism has been formed. Wunder et al. (2008) believed that the most ideal ecological compensation should fully integrate ecological services into the market. Ansink and Houba (2011) systematically studied and evaluated the impact and role of market forces in water extraction, delivery, and water pricing. At present, Germany, the United States, Japan and some other countries have accumulated relatively successful experiences and established a relatively complete ecological compensation framework system.

China began to study the issue of ecological compensation in the early 1990s. Zhang et al. (2013) proposed to calculate the amount of ecological compensation based on the loss of the rights to use resource. Cheng and Kai (2018) reviewed the mature theory and scientific mechanism of watershed ecological compensation, analysed the defects and shortcomings of ecological compensation theory, and provided a theoretical reference for the proposed compensation scheme. In addition, starting from the "Eleventh FiveYear Plan" in 2005, China has listed the construction of ecological compensation mechanism as the main point of work, and proposed the requirements for building it. It has been explored to establish an ecological compensation system in many places ( $\mathrm{Ji}$, 2018). Jiang et al. (2015) analysed the definition, necessity and principle of ecological compensation in the water source area of the inter-basin water transfer project, and studied the theoretical framework of ecological compensation in the water source area.

China is now doing more qualitative compensation studies, and there are few studies on the methods of quantitative compensation.

This paper calculated the ecological compensation amount that should be paid to the water source area by the water receiving area of the central route of the South-to-North Water Deversion Project, and the compensation amount of the four major water receiving areas in Beijing, Tianjin, Hebei and Henan was obtained.

\section{Materials and methods}

\section{Profile of the study area}

The Central Line of the South-to-North Water Diversion Project takes water from the Danjiangkou Reservoir. The total length of the main canal is $1432 \mathrm{~km}$, and the annual average water transfer is 95 billion $\mathrm{m}^{3}$ in recent years. Water is transferred from Hanzhong, Ankang and Shangluo to the main water receiving areas including Beijing, Tianjin, Hebei and Henan. And it provides protection for development of city , industry and agriculture. The diversion route diagram of the South-to-North Water Diversion Project is shown in Figure 1.

The cities as Hanzhong, Ankang and Shangluo have humid climates and abundant rainfall. The average annual rainfall of the three cities is $884.2 \mathrm{~mm}$, which is higher than that in Shaanxi Province. The water resources are very rich. In 2017, the total water resources of Hanzhong, Ankang and Shangluo in southern Shaanxi were 
33.69 billion $\mathrm{m}^{3}$, and the water production modulus was more than twice that of the province (Water Resources Department of Shaanxi Province, 2017).

The water source areas are all poor areas. In 2017, the total GDP of the three cities was 306.5 billion yuan, accounting for only $14 \%$ of the province's GDP. The per capita GDP rankings of Hanzhong City, Ankang City and Shangluo City are ranked lower in the province (Shaanxi Provincial Bureau of Statistics, 2017). Therefore, the state and the water receiving areas are required to provide certain compensation for water source areas.

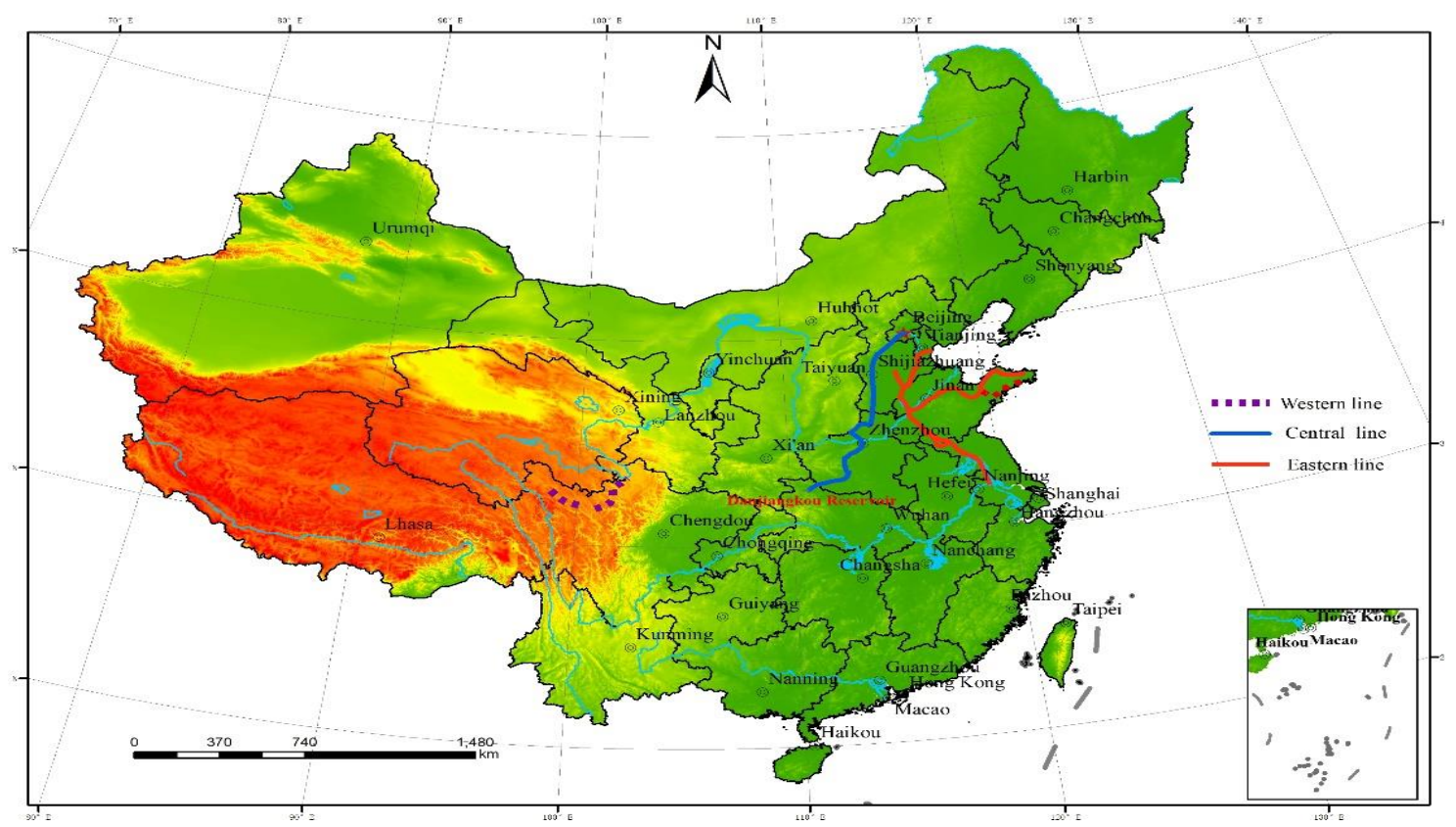

Figure 1. The circuit diagram of the South-to-North Water Diversion Project

\section{Data processing}

Considering the water and soil conservation construction in the water source area, the water market situation in the water management field, the value of water resources and the opportunity cost of future water resources dispatching, the total amount of ecological compensation is calculated. The compensation amount should be paid by the water receiving areas is 6.248 billion yuan/year. Drawing on the distribution ideas of water conservancy project cost allocation (Wang, 2016) and environmental capacity allocation (Chen et al., 2007), the ecological compensation amount payable for each water receiving area is calculated by using the single index method, the comprehensive index method and the deviation method, respectively.

The research basis of this paper is that the first phase of the South-to-North Water Diversion Project has an annual water transfer of 9.5 billion $\mathrm{m}^{3}$, and the water transfer from the Shaanxi Water Source Area is 6.65 billion $\mathrm{m}^{3}$, of which the distribution of water is equal to 0.13 in Beijing, 0.11 in Tianjin, 0.37 in Hebei and 0.4 in Henan.

According to the calculation results, the advantages and disadvantages of various apportion methods are compared and analysed, and a more reasonable apportionment method is determined. 


\section{Methods}

Single indicator method according to water consumption

According to the water consumption of each water receiving area, the average cost pricing method is used for distribution. (Liu, 2007; Zheng and Zhang, 2006). The calculation method is as shown in Equation 1.

$$
C_{i}=\frac{q_{i} \times C}{\sum_{i=1}^{n} q_{i}}
$$

where, $\mathrm{C}_{\mathrm{i}}$ is the shared value of the $\mathrm{i}$-th water receiving area; $\mathrm{C}$ is the total compensation amount; $q_{i}$ is the water consumption of the $i$-th region $(i=1,2 \ldots, n)$. The same meaning in the symbolic sense.

Single indicator method according to the maximum payment capacity of the receiving area

According to the per capita GDP of each water receiving area, the corresponding compensation coefficient is determined. The specific method is as follows:

Assume that $n$ water-receiving areas have GDP of GDP $\mathrm{G}_{\mathrm{i}}$ and population of $\mathrm{p}_{\mathrm{i}}$. The per capita GDP of each region accounts for the ratio of per capita GDP of the waterreceiving area, and the calculation method (Zhang, 2003) is shown in Equation 2.

$$
\alpha_{i}=\frac{\frac{G D P_{i}}{p_{i}}}{\sum G D P_{i}}
$$

Among them, $\alpha_{\mathrm{i}}>1$ indicates that the level of economic development of the $\mathrm{i}$ region is higher than the average level of the water receiving area; $\alpha_{i}<1$ indicates that the level of economic development of the $\mathrm{i}$ region is lower than the average level of the water receiving area; $\alpha_{\mathrm{i}}=1$ indicates that the level of economic development of the $\mathrm{i}$ region is within the average level of the water receiving area. The proportion of compensation fees for each area $\beta_{\mathrm{i}}$ is determined according to the ratio of the per capita GDP of each area to the per capita GDP of the area (Zhang, 2003) and the way to caculate it is shown as Equation 3.

$$
\beta_{i}=\frac{\alpha_{i}}{\sum \alpha_{i}}
$$

\section{Single indicator method according to the value of ecological environment services}

The water diversion project can simultaneously improve the ecological environment service value of the water receiving areas and the water source areas. However, because the value of the ecological environment service of each water receiving area is difficult to define clearly, this paper uses the dry channel coverage and population of water use 
to estimate roughly. The specific algorithm is that the ratio of the length of the main canal in each water receiving area to the total length of the main canal and the proportion of water users to the total population of the water receiving area are determined as 4:6, and the compensation is calculated according to the benefit of each receiving area (Cao and Wang, 2009). Calculations can be done according to Equation 4 and Equation 5.

$$
\begin{gathered}
C_{i}=C \times \delta_{i} \\
\delta_{i}=0.4 \times \frac{1_{i}}{L}+0.6 \times \frac{p_{i}}{P}
\end{gathered}
$$

where $\delta_{\mathrm{i}}$ is the coefficient of eco-environment service value; $l_{\mathrm{i}}$ is the length of the main canal in the $\mathrm{i}$-th water receiving area; $\mathrm{L}$ is the total length of the main canal, which is $1432 \mathrm{~km} ; \mathrm{p}_{\mathrm{i}}$ is the water-receiving population of the $\mathrm{i}$-th water receiving area; $\mathrm{P}$ is the total population of water users.

\section{Comprehensive indicator method}

The comprehensive indicator method is based on the calculation of the selected single-index method which is the comprehensive performance of the single-indicator method. The reasonableness weight of each single-indicator method is evaluated by expert scoring. Drawing on the ideas of the former (Chen et al., 2007) water environment capacity allocation, the proportion of the water consumption, the ability to pay, and the value of the ecological environment service are equal, all of which are $1 / 3$. The methods for calculating them are shown in Equation 6, Equation 7, and Equation 8, respectively.

$$
\begin{gathered}
C_{i}=C \times \frac{\alpha_{i}+\beta_{i}+\delta_{i}}{3} \\
Q_{i}=\frac{q_{i}}{\sum_{i=1}^{n} q_{i}} \\
\beta_{i}=\frac{\alpha_{i}}{\sum_{i=1}^{n} \alpha_{i}}
\end{gathered}
$$

In above equations, $Q_{i}$ is the water consumption coefficient; $\beta_{\mathrm{i}}$ is the coefficient of payment capacity; $\delta_{\mathrm{i}}$ is the coefficient of eco-environment service value.

\section{Deviation method}

The diviation method is not artificially determining the weighting coefficients of various sharing methods, but determining the weight by the degree of single sharing method approaching the average of multiple sharing methods (Chen et al., 2007). It is a 
commonly used and mature sharing method. Suppose there are $\mathrm{n}$ kinds of sharing methods, the average value of the sharing is $\mathrm{x}$, and it is assumed that there is a weighting function $\mathrm{w}_{\mathrm{j}}$. When the sharing coefficient $\mathrm{x}_{\mathrm{j}}$ of the $\mathrm{j}$-th sharing method deviates from the mean $\mathrm{x}$, it indicates that the accuracy of the sharing of the method is poor, and the obtained weight coefficient should be small; otherwise, the weight coefficient should be large.

The estimate $\mathrm{X}$ of the comprehensive sharing coefficient converges to the expected comprehensive sharing coefficient $\overline{\mathrm{X}}$ according to the probability.

\section{Results}

Calculate according to the function constructed by the above methods and results of the three calculation methods are shown in Table 1, Table 2, and Table 3, respectively.

It can be seen from Table 1 that according to the water consumption coefficient, the more water is used, the more compensation will be borne. According to the maximum payment capacity of the receiving area, the economic strength is strong, and the per capita GDP is high, so much more is paid. According to the value of the ecological environment service, the area with high canal coverage and more water users will pay more.

Table 1. Sharing of compensation by single indicator methods (100 million yuan/year)

\begin{tabular}{c|c|c|c|c}
\hline Items & Beijing & Tianjin & Hebei & Henan \\
\hline Water consumption coefficient & 0.13 & 0.11 & 0.37 & 0.40 \\
Compensation amount 1 & 8.11 & 6.87 & 23.10 & 24.97 \\
Ability to pay coefficient & 0.35 & 0.37 & 0.14 & 0.13 \\
Compensation amount 2 & 21.85 & 23.10 & 8.74 & 8.11 \\
Eco-environmental service value & 0.20 & 0.17 & 0.21 & 0.43 \\
$\quad$ coefficient & 12.48 & 10.61 & 13.11 & 26.84 \\
\hline Compensation amount 3 &
\end{tabular}

What can be inferred from Table 2 is that the comprehensive indicator method considers the three impact factors of the single-indicator method, and the calculated result is the average of the three single-indicator methods.

Table 2. Sharing of compensation by the comprehensive index method (100 million yuan / year)

\begin{tabular}{c|c|c|c|c}
\hline Items & Beijing & Tianjin & Hebei & Henan \\
\hline Comprehensive sharing coefficient & 0.23 & 0.22 & 0.24 & 0.32 \\
Compensation amount & 14.15 & 13.52 & 14.98 & 19.97 \\
\hline
\end{tabular}

Using the deviation method to calculate the contribution of each water receiving area $\mathrm{C}_{\text {Beijing }}, \mathrm{C}_{\text {Tianjin }}, \mathrm{C}_{\text {Hebei }}, \mathrm{C}_{\text {Henan, }}$, the sum is not necessarily equal to the total compensation amount C (Zhou, 2009). Therefore, it is necessary to standardize the amount of the contribution calculated by the deviation method. The calculation of the normalization coefficient is shown in Equation 9. 


$$
\varepsilon=\frac{C}{C_{\text {Beijing }}+C_{\text {Tianjin }}+C_{\text {Hebei }}+C_{\text {Henan }}}
$$

After standardization and adjustment, it can get 1.323 billion yuan/year in Beijing, 1.194 billion yuan/year in Tianjin, 1.40 billion yuan/year in Hebei Province, and 2.331 billion yuan/year in Henan Province.

Table 3. Sharing of compensation by the deviation method (100 million yuan / year)

\begin{tabular}{c|c|c|c|c|c}
\hline Items & Beijing & Tianjin & Hebei & Henan & Sum \\
\hline Water weight & 0.32 & 0.35 & 0.20 & 0.44 & \\
Payment weight & 0.19 & 0.18 & 0.32 & 0.17 & \\
Ecological service weight & 0.48 & 0.47 & 0.48 & 0.39 & \\
sharing factor X & 0.21 & 0.19 & 0.22 & 0.36 & 0.97 \\
Compensation amount & 12.86 & 11.61 & 13.61 & 22.66 & 60.67 \\
\hline
\end{tabular}

\section{Comparison of different allocation methods}

Make a comparison of calculation results of different methods (Figure 2), and compare the advantages and disadvantages of these methods.

Single indicator method: The calculation results are unstable and one-sided. The calculation process is simple, but using different indicators to calculate, the results shared by each water-receiving area are very different, which is easy to lead to doubts about the reliability of the methods and data used.

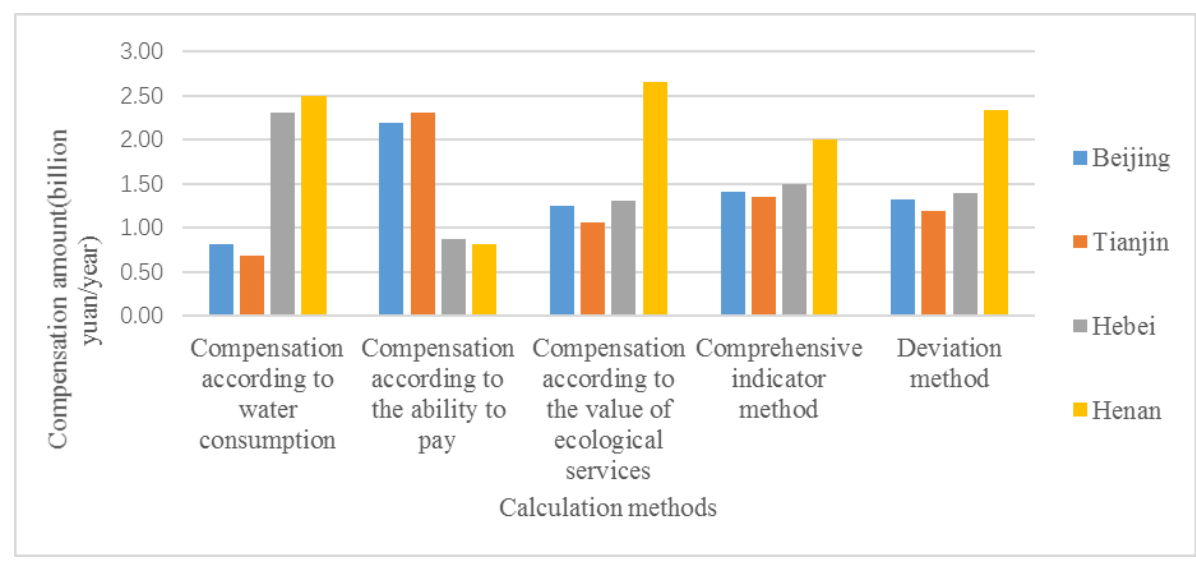

Figure 2. Comparison of calculation results of different methods

Comprehensive indicator method: Compared with the comprehensive indicator method, the results are more stable, but the proportion of each individual indicator is artificially determined. It is very subjective, and its objectivity and fairness are easily questioned.

Deviation method: Considering a variety of factors, and the sharing coefficient is determined according to the mathematical model rather than artificial distribution, and the sharing process is transparent and open. Therefore, the method of deviation is a more comprehensive and objective method of compensation. 


\section{Discussion}

Analysis of the rationality of using the deviation method:

1. It is assumed that the net benefit of national economic use in a certain year after 2018 is $B_{d}$, and the annual compensation for ecological construction is $C_{d}$. The benefitto-input ratio is $\mathrm{Kd}$ and the way to calculate it is shown in Equation 10.

$$
K_{d}=\frac{B_{d}}{C_{d}}
$$

When $K_{d} \leq 1$, the ecological compensation amount of the water receiving area exceeds the amount of benefits it receives, which will make the project lose its economic significance, so it is necessary to make $K_{d}>1$ (Shi et al., 2009). According to the experts of the Yangtze River Water Resources Commission, the direct benefits of the Central Line of the South-to-North Water Diversion Project in terms of water supply and flood control are estimated to have an average annual benefit of 45.6 billion yuan per year. From the difference flat method, the amount of water-receiving burden is 6.248 billion yuan/year, which is far less than the comprehensive benefit of citing water resources, and there is $\mathrm{K}_{\mathrm{d}}>1$.

2. According to the principle of individual rationality, the amount of compensation undertaken by the participating regions should not be greater than the cost of water resources from other sources. Otherwise, the payment will be too high to pay the ecological compensation.

In 2018, the value of surface water resources in Tianjin is $4 \mathrm{yuan} / \mathrm{m}^{3}$, and the value of surface water resources in Beijing is about 3.64 yuan $/ \mathrm{m}^{3}$. The value of water resources will continue to increase. The second phase of the Central Line of the Southto-North Water Diversion Project has a water transfer capacity of 6.65 billion $\mathrm{m}^{3} /$ year from Shaanxi, which means that the value of the water resources from Shaanxi water source area of the Central Line of the South-North Water Diversion Project in 2019 is 0.94 yuan $/ \mathrm{m}^{3}$. It can be seen that the cost of citing water from Shaanxi water source area is much less than the cost of obtaining water resources from other sources.

\section{Conclusions}

1. The method of deviation is the most comprehensive and objective method for calculating the ecological compensation sharing method.

2. Using the deviation method to share the ecological compensation amount of Shaanxi water source area, the scores are 1.323 billion yuan/year in Beijing, 1.194 billion yuan/year in Tianjin, and 1.40 billion yuan/year in Hebei Province, Henan. The province has 2.31 billion yuan / year.

This paper only puts forward a basic idea of inter-basin water transfer ecological compensation sharing, and does not give a clear commentary on the specific implementation of ecological compensation. And there is no specific details of the implementation process of an ecological compensation mechanism, such as the way to make collection of compensation funds, methods for solving water pollution problems along the central line of the South-to-North Water Deversion Project and some other measures. It is recommended that future research can be carried out in these directions to ensure a smoother and healthier compensation mechanism. 
Acknowledgements. This research is financially supported by "Fundamental Research Funds for the Cen tral Universities No. XDJK2019F002" and Chongqing social livelihood key research and development pr ojects, No.cstc2018jscX-mszdX0052, and the support was gratefully acknowledged.

\section{REFERENCES}

[1] Ansink, E., Houba, H. (2011): Market Power in Water Markets. - Journal of Environment al Economics and Management 64(2): 237-252.

[2] Brown, M. A., Clarkson, B. D., Stephens, R. T., Barton, B. J. (2014): Compensating for ecological harm - the 2008 state of play in New Zealand. - New Zealand Journal of Ecology 1: 139-146.

[3] Cao, M. D., Wang, F. Y. (2009): Study on the legal issues of Inter-basin Water Diversion ecological compensation: Taking the water source area (Henan part) of the central route of the South-to-North Water Diversion Project as an example. - Journal of Graduate School of the Chinese Academy of Social Sciences 12: 6-13.

[4] Chen, J., Huang, W. (2006): Risks and countermeasures of Inter-basin Long-distance Water Diversion Project. - China Water Resources 114: 11-14.

[5] Chen, D. J., Lu, J., Jin, S. Q. (2007): Estimation and allocation of water environment capacity of non-point source polluted rivers. - Entironmental science 128: 1416-1423.

[6] Cheng, X., Kai, F. (2018): Research Review of Ecological Compensation Mechanism in Drainage Basin. - Journal North China University Water Resources Electric Power 34: 913.

[7] Hansen, K., Duke, E., Bond, C., Purcell, M., Paige, G. (2018): Rancher preferences for a payment for ecosystem services program in Southwestern Wyoming. - Ecological Economics 146: 240-249.

[8] Ji, P. C. (2018): Accelerate the improvement of ecological compensation mechanism in China's river basins. - Environmental Protection: 41-46.

[9] Jiang, R. G., Xie, J. C., Zhu, J. W. (2015): Theoretical framework of ecological compensation in water source area of inter-basin water transfer project. - Bulletin of Soil and Water Conservation 35: 273-277.

[10] Liu, Y. L. (2007): Ecological compensation and watershed ecological co-construction and sharing. - China Water Resources and Hydropower Press, Beijing.

[11] Shaanxi Provincial Bureau of Statistics (2017): Shaanxi Statistical Yearbook. - China Statistics Press.

[12] Shi, S. J., Li, H. E., Lin, Q. C. (2009): Study on the method of sharing ecological compensation amount of inter-basin water transfer. - Journal of Hydraulic Engineering 40: $268-273$.

[13] Thieme, M. L., Rudulph, J., Higgins, J., Takats, J. A. (2012): Protected areas and freshwater conservation: a survey of protected area managers in the Tennessee and Cumberland River Basins, USA. - Journal of Environmental Management 109: 189-199.

[14] Wang, H. N. (2016): Hydropower project investment cost sharing method and application. - Communication of Finance and Accounting: 73-77.

[15] Water Resources Department of Shaanxi Province (2017): 2016 Shaanxi Water Resources Bulletin.

[16] Wunder, S., Engel, S., Pagiola, S. (2008): A Comparative Analysis of Payments for Environmental Services Programs in Developed and Developing Countries. - Ecological Economics 65: 834-852.

[17] Zhang, C. L. (2003): Research on compensation mechanism of water resources recover. China Institute of Water Resources and Hydropower Research, Beijing.

[18] Zhang, H. Y., Liu, G. G. (2006): Design of ecological compensation mechanism for river basins in China. - Environmental Protection 10(A): 49-54. 
[19] Zhang, J., Yang, J. X., Chen, X. (2013): Study on the calculation method of water resources ecological compensation quota in river basin. - Chinese Society of Environmental Sciences Academic Annual Meeting: 10W-1097.

[20] Zhang, M., Zhou, J. H., Zhou, R. J. (2018): Interval Multi-Attribute Decision of Watershed Ecological Compensation Schemes Based on Projection Pursuit Cluster. Water 10: 1280-1282.

[21] Zheng, H. X., Zhang, L. B. (2006): Study on quantitative standards for compensation of watershed ecological services. - Environmental Protection 1(A): 42-46.

[22] Zhou, Z. P. (2009): Application of deviation method in compensation distribution in water-receiving areas. - Information Technology Market Weekly Theoretical Research: 141-142. 